\title{
Effects of Continuous Positive Airway Pressure Therapy in Three Japanese Patients with Obstructive Sleep Apnea and Resistant Hypertension
}

\author{
Hiromitsu Sekizuka, Naohiko Osada and Fumihiko Miyake
}

\begin{abstract}
The following three case reports present the effects of 6-month continuous positive airway pressure (CPAP) therapy on blood pressure (BP) in severe obstructive sleep apnea patients with resistant hypertension. Case 1 A 58-year-old woman exhibited a decreased 24-hour BP and changes in the nocturnal BP dipping pattern from non-dipper to dipper. Case 2 A 64-year-old man showed no improvements in nocturnal BP. Case 3 A 78-year-old man with ischemic cardiomyopathy exhibited changes in the nocturnal BP dipping pattern from non-dipper to dipper. These results suggest that 6-month CPAP therapy improves the nocturnal BP dipping status in some patients with obstructive sleep apnea and resistant hypertension.
\end{abstract}

Key words: polysomnography, ambulatory blood pressure monitoring, sleep-disordered breathing, positive airway pressure, circadian rhythm

(Intern Med 52: 2241-2244, 2013)

(DOI: 10.2169/internalmedicine.52.0363)

\section{Introduction}

The mechanisms of obstructive sleep apnea (OSA) are closely associated with the development of hypertension. The incidence of resistant hypertension is particularly high in OSA patients, in spite of the use of three or more antihypertensive agents from different classes (1). Continuous positive airway pressure (CPAP) therapy also exerts hypotensive effects on OSA patients with resistant hypertension. The effects of CPAP therapy in Westerners have been reported $(2,3)$; however, only a handful of case reports of Japanese patients have been published. We herein report the hypotensive effects of CPAP therapy in Japanese OSA patients with resistant hypertension.

\section{Case Reports}

\section{Materials and methods}

This case report includes the cases of three Japanese patients with resistant hypertension who exhibited uncontrolled blood pressure (BP; clinic BP $\geq 140 / 90 \mathrm{mmHg}$ ) despite receiving treatment with three or four antihypertensive drugs. All risk factors for secondary hypertension, except for OSA, were ruled out based on the findings of ultrasonography, magnetic resonance imaging (MRI), computed tomography (CT) and blood sampling. The presence of OSA was determined using full polysomnography (PSG) with the SLEEP WATCHER $^{\circledR}$ (Compedics, Australia). Clinic BP was measured twice in our outpatient facility between 09:00 and 17:00 according to the cuff-oscillometric method using an electronic arm cuff device in the sitting position after 3-5 minutes of rest. Noninvasive ambulatory BP monitoring (ABPM) was performed for 24 hours using an FM- $800^{\circledR}$ [Fukuda Denshi Ltd., Tokyo, Japan (4)] at 30-minute intervals before and after six months of CPAP therapy (5). The average duration of CPAP use was calculated using a memory card embedded in the CPAP machines. The ABPM data were analyzed based on the method described by Kario et al. [Fig. 1 (6)]. Each patient recorded when they fell asleep at night and woke in the morning on the ABPM. The study protocol was approved by the St. Marianna University School of Medicine Institutional Committee on Human Re-

Division of Cardiology, Department of Internal Medicine, St. Marianna University School of Medicine, Japan

Received for publication February 14, 2013; Accepted for publication May 23, 2013

Correspondence to Dr. Hiromitsu Sekizuka, sekimal@marianna-u.ac.jp 


\begin{tabular}{|c|c|c|}
\hline \multicolumn{3}{|c|}{$\begin{array}{l}\text { Hypertension: } \geq 24 \text {-hour blood pressure } 130 / 80 \mathrm{mmHg} \\
\text { Normal blood pressurer: < 24-hour blood pressure } 130 / 80 \mathrm{mmHg} \\
\text { Nocturnal hypertension: } \geq \text { nocturnal blood pressure } 120 / 70 \mathrm{mmHg}\end{array}$} \\
\hline \multicolumn{3}{|c|}{ Nocturnal blood pressure dipping patterns } \\
\hline Dippers: & BP/ & ) $\geq 10 \%$ but $<20 \%$ \\
\hline Non-dippers: & $\| 1$ & $\geq 0 \%$ but $<10 \%$ \\
\hline Risers: & $\pi$ & $<0 \%$ \\
\hline Extreme dippers: & $\not /$ & $\geq 20 \%$ \\
\hline
\end{tabular}

Figure 1. Circadian blood pressure changes. The circadian blood pressure was assessed using ambulatory blood pressure monitoring (ABPM) (6). SBP: systolic blood pressure

search. Informed consent was obtained from all patients prior to enrollment.

\section{Case 1}

A 58-year-old woman had a history of snoring for several years. In 2010, she presented to our hospital with suspected OSA, a contributing factor for resistant hypertension. Upon hospital arrival, her height was $154 \mathrm{~cm}$, her body weight was $61.0 \mathrm{~kg}$ and her body mass index (BMI) was $25.7 \mathrm{~kg}$ / $\mathrm{m}^{2}$. Her previous medical history included the use of antihypertensive therapy since 2008 (olmesartan: $40 \mathrm{mg}$, amlodipine: $5 \mathrm{mg}$, trichlormethiazide: $2 \mathrm{mg}$ ) and reflux esophagitis with no alcohol intake or smoking habits. The results of 24-hour ABPM suggested that the patient had hypertension (24-hour BP, 131.8/84.2 mmHg), nocturnal hypertension and a non-dipper status with a $6 \%$ night-time BP decline (Table 1, Fig. 2). The Epworth sleepiness score (ESS) was 4 points. The patient's sleep study data are shown in Table 2. She was diagnosed with severe OSA, and CPAP therapy was initiated following the titration of pressure at pressure limits of 4 to $10 \mathrm{~cm} \mathrm{H}_{2} \mathrm{O}$ (Table 2). The average duration of CPAP use was 6.5 hours/night, and the patient experienced no changes in prescribed medications during the treatment period. After six months of CPAP therapy, the ESS was 4 points, the patient's BMI was $26.1 \mathrm{~kg} / \mathrm{m}^{2}$ and ABPM revealed a normal BP, nocturnal hypertension and an improved nocturnal BP dipping pattern from a non-dipper $(6 \%)$ to a dipper (11\%) status (Table 1, Fig. 2).

\section{Case 2}

A 64-year-old man was diagnosed with hypertension in 2005. Upon hospital arrival, his height was $161 \mathrm{~cm}$, his body weight was $66.9 \mathrm{~kg}$ and his BMI was $25.8 \mathrm{~kg} / \mathrm{m}^{2}$. He was an opportunity drinker and had given up smoking 10 years earlier. The prescribed medications included telmisar$\tan (80 \mathrm{mg})$, azelnidipine $(16 \mathrm{mg})$, carvedilol $(10 \mathrm{mg})$ and trichlormethiazide $(2 \mathrm{mg})$. The results of 24-hour ABPM suggested that the patient had hypertension (24-hour BP, 146.1/79.5 mmHg), nocturnal hypertension and a non-dipper status with a night-time BP decline of only $3 \%$ (Table 1, Fig. 2). The ESS was 8 points. The results of PSG are shown in Table 2. CPAP titration was performed to obtain a detailed evaluation. CPAP therapy was subsequently initiated following titration of the lower and upper pressures to 4 and $12 \mathrm{~cm} \mathrm{H}_{2} \mathrm{O}$, respectively. The patient experienced no changes in prescribed medications throughout the treatment period. After six-months of CPAP therapy, the patient lost $0.4 \mathrm{~kg}$ in weight and his BMI was $25.7 \mathrm{~kg} / \mathrm{m}^{2}$, the average duration of CPAP use was 4.0 hours/night, the ESS was 4 points and ABPM showed nocturnal hypertension and a non-dipper pattern with a $5 \%$ night-time BP decline (Table 1, Fig. 2).

\section{Case 3}

A 78-year-old man was admitted to our hospital with dyspnea and pitting edema of the lower extremities in 2010. He was diagnosed with congestive heart failure due to ischemic cardiomyopathy and an old antero-septal myocardial infarction. His medical history included a prior acute myocardial infarction, hypertension and dyslipidemia diagnosed 10 years earlier. Since frequent snoring and apnea were evident during admission, he was suspected to have OSA and underwent ABPM and PSG two months after discharge. His height was $157 \mathrm{~cm}$, his body weight was 62.1 $\mathrm{kg}$ and his BMI was $25.2 \mathrm{~kg} / \mathrm{m}^{2}$. He did not drink alcohol or smoke cigarettes. His medications included candesartan (8 $\mathrm{mg}$ ), carvedilol $(10 \mathrm{mg}$ ) and furosemide $(20 \mathrm{mg})$. Transthoracic echocardiography showed decreased left ventricular wall motion and thickening in the anterior and septal walls of the left ventricle. The Simpson's left ventricular ejection fraction was $32 \%$. The left ventricular end-diastolic and endsystolic dimensions were $64 \mathrm{~mm}$ and $54 \mathrm{~mm}$, respectively. Color Doppler echocardiography showed no significant valvular heart disease. The ratio of the early diastolic mitral flow velocity to the early diastolic mitral annular velocity was 12.0. The laboratory data showed a hemoglobin level of $9.7 \mathrm{~g} / \mathrm{dL}$, a creatinine level of $0.95 \mathrm{mg} / \mathrm{dL}$, a blood urea nitrogen level of $14.0 \mathrm{mg} / \mathrm{dL}$ and a brain natriuretic peptide level of $125.4 \mathrm{pg} / \mathrm{mL}$. The results of 24-hour ABPM suggested that the patient had hypertension (24-hour BP, 142.9/ $79.7 \mathrm{mmHg}$ ), nocturnal hypertension and a non-dipper status with an $8 \%$ night-time BP decline (Table 1, Fig. 2). The ESS was 0 points. Table 2 shows the results of PSG. The patient received CPAP therapy following titration of the pressure limits at 4 to $12 \mathrm{~cm} \mathrm{H}_{2} \mathrm{O}$. The average duration of CPAP use was $5.6 \mathrm{~h} / \mathrm{night}$, and the patient experienced no prescribed medication changes during the treatment period. After six-months of CPAP therapy, the patient's BMI was $25.1 \mathrm{~kg} / \mathrm{m}^{2}$ and ABPM showed nocturnal hypertension and a dipper pattern with a decreased night-time BP (14\%; Table 1 and Fig. 2).

\section{Discussions}

OSA is readily diagnosed and usually treatable, although it is a risk factor for resistant hypertension, which is often uncontrollable, even with the use of three or more antihypertensive agents (1). Kario (7) recommended the use of CPAP therapy in OSA patients with an AHI of $\geq 20$ /hour 
Table 1. Changes in Blood Pressure before and after Six-months of Continuous Positive Airway Pressure Therapy

\begin{tabular}{llccccc}
\hline Period & $\begin{array}{c}\text { Clinic BP } \\
\text { (mmHg) }\end{array}$ & $\begin{array}{c}\text { 24-hour BP } \\
\text { (mmHg) }\end{array}$ & $\begin{array}{c}\text { Diurnal BP } \\
\text { (mmHg) }\end{array}$ & $\begin{array}{c}\text { Nocturnal BP } \\
\text { (mmHg) }\end{array}$ & $\begin{array}{c}\text { Dipping } \\
\text { status (\%) }\end{array}$ \\
\hline \multirow{2}{*}{ Case 1 } & Baseline & $157 / 96$ & $131.8 / 84.2$ & $134.7 / 87.4$ & $127.1 / 79.1$ & 6 \\
& 6 months & $132 / 88$ & $121.8 / 78.6$ & $125.9 / 80.2$ & $112.4 / 75.1$ & 11 \\
Case 2 & Baseline & $148 / 72$ & $146.1 / 79.5$ & $148.5 / 81.3$ & $135.9 / 71.9$ & 3 \\
& 6 months & $134 / 60$ & $148.8 / 76.8$ & $157.0 / 83.4$ & $134.4 / 65.2$ & 5 \\
Case 3 & Baseline & $161 / 93$ & $142.9 / 79.7$ & $144.6 / 82.9$ & $140.4 / 74.9$ & 8 \\
& 6 months & $126 / 72$ & $137.8 / 70.9$ & $140.9 / 72.4$ & $133.7 / 69.0$ & 14 \\
\hline
\end{tabular}

BP: blood pressure

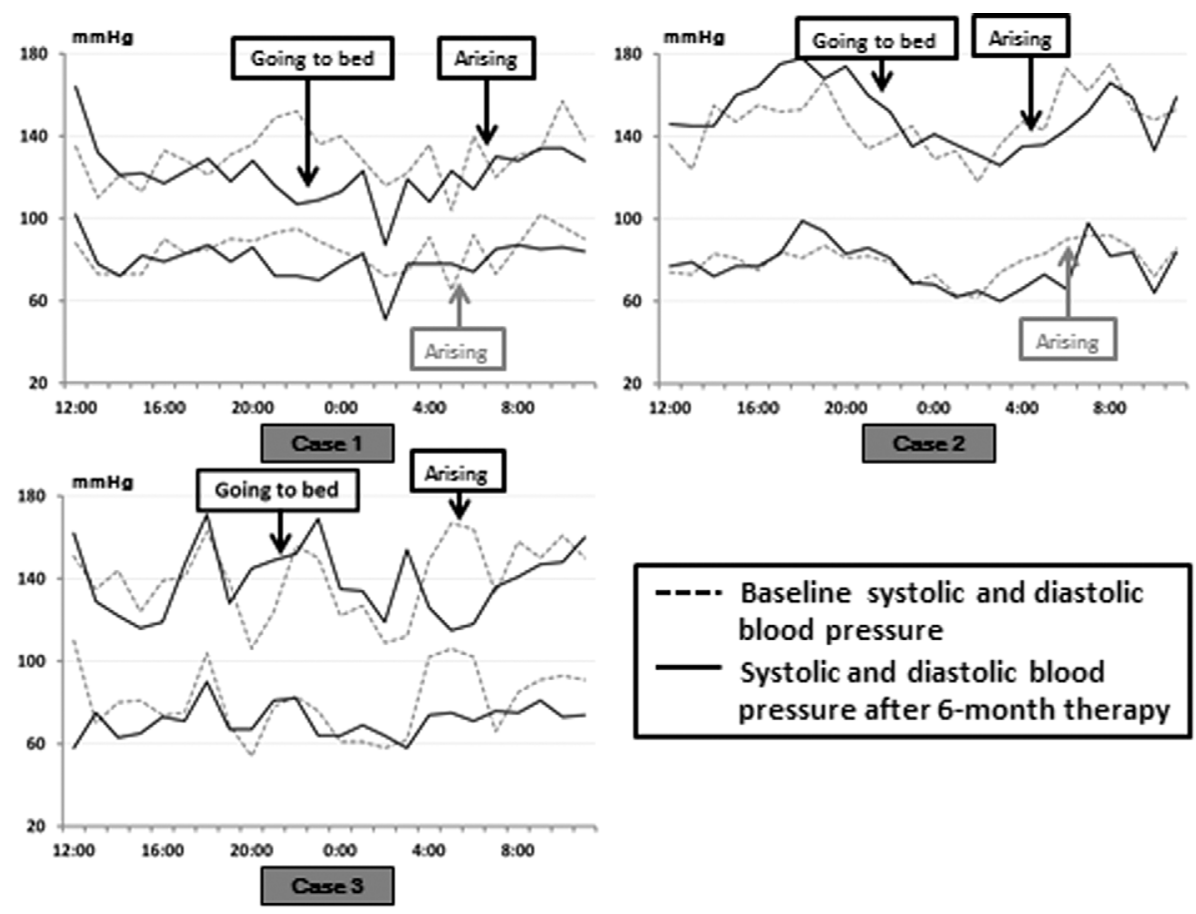

Figure 2. Blood pressure before and after six-months of continuous positive airway pressure therapy. The patients' blood pressure was measured at 30-minute intervals using ABPM. This figure presents the blood pressure values obtained at 1-hour intervals using ABPM. Decreases in 24-hour blood pressure, diurnal blood pressure and nocturnal blood pressure were observed in Cases 1 and 3. In addition, the dipping status improved in Cases 1 and 3.

complicated by hypertension. Bazzano et al. (2) reviewed 255 reports of 16 randomized clinical trials and concluded that 2-week CPAP therapy decreases the BP values in OSA patients. Akashiba et al. (8) reported that 3-day CPAP therapy reduces diurnal and nocturnal $\mathrm{BP}$ and results in changes from a "non-dipper" to a "dipper" status in OSA patients. Lozano et al. (3) demonstrated that, in their study, 3-month CPAP treatment achieved reductions in 24-hour systolic BP (-9.71 $\mathrm{mmHg})$, 24-hour diastolic BP (-6.98 $\mathrm{mmHg})$, and daytime diastolic BP $(-6.12 \mathrm{mmHg})$ in OSA patients with ABPM-confirmed resistant hypertension. These results were obtained from small- to large-scale studies $(2,3,8)$; therefore, the hypotensive effects of CPAP therapy may vary among patients with different backgrounds. In addition, most earlier studies of OSA were conducted in the West and included relatively obese patients. It thus remains uncertain whether the results of these studies are applicable to nonobese Japanese patients with OSA.

Of our patients with resistant hypertension, two (Cases 1 and 3) exhibited improvements in the nocturnal BP dipping status after six-months of CPAP therapy and one (Case 2) did not. Heart failure patients with a reduced ejection fraction, as observed in Case 3, tend to exhibit a non-dipper pattern (9), although, in both Cases 1 and 3, the nocturnal BP dipping pattern changed from a non-dipper to a dipper status following the administration of CPAP therapy. A nondipper status is associated with the prognosis of end-organ damage $(6,10)$. In our cases, particularly Case 2 , no significant decreases in BP were observed. This finding was presumed to be due to the patients' older age (11), lower BMI compared with that of study patients evaluated in published reports in Europe and the United States $(2,12)$ and short 
Table 2. Sleep Study Data

\begin{tabular}{|c|c|c|c|c|c|c|c|c|c|c|}
\hline & Period & AHI (/h) & $\mathbf{A I}(/ \mathbf{h})$ & $\mathrm{CA}(/ \mathbf{h})$ & OA (/h) & MA (/h) & $\begin{array}{c}\text { Arousal } \\
\text { index (/h) }\end{array}$ & $\begin{array}{c}\text { Sleep s tage } \\
3+4(\%)\end{array}$ & $\begin{array}{c}\text { REM sleep } \\
(\%)\end{array}$ & $\begin{array}{l}\text { lowest oxygen } \\
\text { saturation (\%) }\end{array}$ \\
\hline \multirow{2}{*}{ Case 1} & Baseline & 38.1 & 11.6 & 0.3 & 11.2 & 0.1 & 32.1 & 6.5 & 11.9 & 79 \\
\hline & After CPAP titration & 4.9 & 0.4 & 0.4 & 0.0 & 0.0 & 22.5 & 36.0 & 15.7 & 93 \\
\hline \multirow{2}{*}{ Case 2} & Baseline & 51.2 & 47.0 & 2.3 & 44.3 & 0.4 & 62.0 & 0.0 & 9.2 & 80 \\
\hline & After CPAP titration & 1.5 & 1.0 & 0.2 & 0.8 & 0.0 & 23.6 & 9.8 & 15.8 & 94 \\
\hline \multirow{2}{*}{ Case 3} & Base line & 90.4 & 76.5 & 3.8 & 69.8 & 2.9 & 103.9 & 0.0 & 13.8 & 76 \\
\hline & After CPAP titration & 3.8 & 0.5 & 0.3 & 0.2 & 0.0 & 17.5 & 11.3 & 19.7 & 90 \\
\hline
\end{tabular}

AHI: apnea-hypopnea index, AI: apnea index, CA: central apnea, OA: obstructive apnea, MA: mixed apnea, REM: rapid eye movement,

CPAP: continuous positive airway pressure

duration of CPAP use (2). Meanwhile, intermittent hypoxia in patients with OSA influences the progression of cardiovascular disorders $(13,14)$. The hypotensive effects of CPAP therapy on OSA associated with resistant hypertension were insufficient in our patients, although CPAP therapy does improve hypoxia, which results in a better prognosis of OSA. Accordingly, the outcomes of our patients suggest that CPAP therapy is likely associated with a better long-term prognosis and that its effects differ in OSA patients with resistant hypertension with different backgrounds.

We herein presented the cases of three severe OSA Japanese patients with resistant hypertension who were treated with CPAP therapy, which resulted in improvements in the dipping status and prognosis. Further data accumulation with larger study populations is required to verify the effects of CPAP therapy.

The authors state that they have no Conflict of Interest (COI).

\section{References}

1. Pedrosa RP, Drager LF, Gonzaga CC, et al. Obstructive sleep apnea: the most common secondary cause of hypertension associated with resistant hypertension. Hypertension 58: 811-817, 2011.

2. Bazzano LA, Khan Z, Reynolds K, He J. Effect of nocturnal nasal continuous positive airway pressure on blood pressure in obstructive sleep apnea. Hypertension 50: 417-423, 2007.

3. Lozano L, Tovar JL, Sampol G, et al. Continuous positive airway pressure treatment in sleep apnea with resistant hypertension: a randomized, controlled trial. J Hypertens 28: 2161-2168, 2010.

4. Nakamura K, Kikuya M, Hara, et al. Validation of the FM-800 ambulatory blood pressure monitor according to the Association for the Advancement of Medical Instrumentation criteria and the
International Protocol. Clin Exp Hypertens 32: 523-527, 2010.

5. Sekizuka H, Kida K, Akashi YJ, et al. Relationship between sleep apnea syndrome and sleep blood pressure in patients without hypertension. J Cardiol 55: 92-98, 2010.

6. Kario K, Pickering TG, Umeda Y, et al. Morning surge in blood pressure as a predictor of silent and clinical cerebrovascular disease in elderly hypertension: a prospective study. Circulation 107: 1401-1406, 2003.

7. Kario K. Obstructive sleep apnea syndrome and hypertension: mechanism of the linkage and 24-h blood pressure control. Hypertension Res 32: 537-541, 2009.

8. Akashiba $\mathrm{T}$, Minemura $\mathrm{H}$, Yamamoto $\mathrm{H}$, Kosaka N, Saito O, Horie T. Nasal continuous positive airway pressure changes blood pressure "non-dippers" to "dippers" in patients with obstructive sleep apnea. Sleep 22: 849-853, 1999.

9. Goyal D, Macfadyen RJ, Watson RD, Lip GY. Ambulatory blood pressure monitoring in heart failure: a systematic review. Eur $\mathbf{J}$ Heart Fail 7: 149-156, 2005.

10. Lurbe E, Redon J, Kesani A, et al. Increased in nocturnal blood pressure and progression to microalbuminuria in type 1 diabetes. N Engl J Med 347: 797-805, 2002.

11. Haas DC, Foster GL, Nieto FJ, et al. Age-dependent associations between sleep-disordered breathing and hypertension: importance of discriminating between systolic/diastolic hypertension and isolated systolic hypertension in the Sleep Heart Health Study. Circulation 111: 614-621, 2005.

12. Robinson GV, Langford BA, Smith DM, Stradling JR. Predictors of blood pressure fall with continuous positive airway pressure (CPAP) treatment of obstructive sleep apnoea (OSA). Thorax $\mathbf{6 3}$ : 855-859, 2008.

13. Dematteis $M$, Julien $C$, Guillermet $C$, et al. Intermittent hypoxia induces early functional cardiovascular remodeling in mice. Crit Care Med 177: 227-235, 2008.

14. Savransky V, Nanayakkara A, Li J, et al. Chronic intermittent hypoxia induces atherosclerosis. Am J Respir Crit Care Med 175: 1290-1297, 2007.

(C) 2013 The Japanese Society of Internal Medicine http://www.naika.or.jp/imonline/index.html 